Dr Plant and Professor Glynn reply: Bradley's observation that in strains of inbred mice resistance to infection with Leishmania donovani is either very high or very low and corresponds to the level of resistance to Salmonella typhimurium found by us in six of the same strains reinforces the idea that resistance is controlled by only one or a few closely linked genes.

Like him, we do not find in further breeding experiments that resistance is invariably associated with a particular $H-2$ type. But because of our results with delayed hypersensitivity reactions as well as on general grounds we do believe that some sort of enhanced immune response is involved. Both $S$. typhimurium and $L$. donovani are intracellular parasites and cellular immunity is the most important defence mechanism in both. It is unlikely though not impossible that there is a significant protective antigen common to $S$. typhimurium and $L$. donovani, though it is also unlikely that anyone has actually looked for one. An immune response gene controlling responses to several unrelated antigens would explain the results.

Department of Bacteriology,

St Mary's Hospital Medical School,

London, UK

'Plant, J., and Glynn, A. A., Nature, 248 $345-347$ (1974).

${ }^{2}$ Stauber, L. A., Rice Institute Pamphlet, 45, 80-96 (1958)

${ }^{3}$ Goodwin, L. G., Trans. R. Soc. trop. Med. Hyg., 38, 151-160 (1944).

\section{Area postrema and blood pressure}

SIR,-Ylitalo et al. ${ }^{1}$ based their suggestion that the area postrema is a control centre of blood pressure on experiments in which a maintained rise in the level of blood pressure, which was also more labile than normal, followed destruction of the area postrema in rats. As it is well known, however, that such effects are produced by section of the buffer nerves ${ }^{8}$, the possibility must be considered that the baroreceptor pathway could have been interrupted where the sinus and aortic nerves terminate in the medulla in the nucleus of the tractus solitarius ${ }^{3,4}$, which lies immediately adjacent to the area postrema.

We suggest, therefore, that a simpler explanation of the results ${ }^{1}$ is that the damage caused by thermocoagulation of the area postrema had spread the fraction of a millimetre necessary to involve the nucleus of the tractus solitarius. In the absence of evidence that the baroreceptor pathway had been spared, it is not justified to put forward the suggestion that the area postrema acts as a special blood pressure regulating centre.

Yours faithfully,

$$
\begin{aligned}
& \text { S. M. Hilton } \\
& \text { R. M. McAllen } \\
& \text { K. M. Spyer }
\end{aligned}
$$

Department of Physiology,

The Medical School,

The University of Birmingham,

Birmingham B15 2TJ, UK

1 Ylitalo, P., Karppanen, H., and Paasonen, M. K., Nature, 247, 58-59 (1974).

2 Ferrario, C. M., McCubbin, J. W., and Page, I. H., Circ. Res., 24, $911-922$ (1969). 3 Torvik, A., J. comp. Neurol., 106, 51-141 (1956).

${ }^{4}$ Humphrey, D. R., in Baroreceptors and Hypertension, (edit. by Kezdi, P.) (Pergamon, 1967).

\section{On fighting strategies in animal combat}

SIR,-The article ${ }^{1}$ by Maynard Smith and Price is unfortunately based on a number of unwarranted assumptions, and on an inadequate literature research. It perpetuates an old ethological myth that animals fight so as not to injure each other, or refuse to strike 'foul blows' and, presumably, kill each other. The authors assumed that there were such categories as 'conventional' and 'dangerous' in animal conflict, that opponents in combat retreat when injured, and that opponents retain no memory of past contests. None of these assumptions can be regarded as valid. They were not aware of the published field studies primarily of large mammals which have shown not only how dangerous combat is, but, more importantly, have also led to new theories of explaining aggressive behaviour on the basis of individual selection ${ }^{2-10}$

Two authors at least ${ }^{2,3,11}$ have developed the concept that combat can be understood as an interplay of defensive and offensive behaviour. This is a simple point but one missed previously, and one that leads to the conclusion that animals need not rely on altruistic impulses in their opponents to escape injury, but rely on their abilities to block, evade or frustrate attacks. First, the inhibition against engagement in overt aggression in species with excellent weapons but poor morphological or behavioural defences can be explained by the principle of retaliation ${ }^{2,3}$. This explanation assumes that an animal will attack a conspecific if it experiences severe pain, an assumption amply verified ${ }^{12,13}$. Second, it assumes that even dangerously armed species (excepting humans) usually cannot kill an opponent outright and thus escape retaliation. This second assumption is entirely in line with data from diverse field studies on carnivores and ungulates ${ }^{2-9.14}$.

The authors also become victims of one study of mule deer which can be faulted for inadequate observations. Linsdale and Tomich $^{15}$ in their work apparently failed to see a fight between mule deer bucks and confused the common sparring matches with fighting. Sparring matches are performed by bucks of unequal size or dominance rank; they are initiated by the subordinate buck and terminated by him; they are long lasting with many engagements and have antler wrestling as their principal behavioural component. Fights are exceedingly rare, occur between matched bucks, and differ strikingly in their execution from sparring matches; moreover the victor chases and attempts to gore the vanquished. There are no 'winners' or 'losers' in sparring matches. Severe wounding does occur in mule deer, usually on smaller bucks unable to withdraw from onrushing dominants which guard females. Flanks, shoulders, haunches and faces are pierced; the rate of visible wounding is about $10 \%$ $\mathrm{yr}^{-1}$ among bucks exceeding $1.5 \mathrm{yr}$ of age. I shall report in detail on this in the near future.

Yours faithfully, V. GeIst

Faculty of Environmental Design,

The University of Calgary,

Calgary, Alberta, Canada, T2N 1N4

1 Maynard Smith, J., and Price, G. R., Nature, 246, 15 (1973).

${ }^{2}$ Geist, V., Behaviour, 27, 175 (1966).

${ }^{3}$ Geist, V., Mountain sheep: A Study in Behaviour and Evolution, chapter 7 (University of Chicago Press, Chicago and London, 1971).

- Bannikov, A. G., Ahirnov, L. V., Lebedeva, L. S., and Fandee, A. A., Biology of the Saiga. (US Department of Commerce, Springfield, Virginia, 1961).

${ }^{5}$ Kurt, F., Das Sozialverhalten des Rehes Capreolus capreolus, L. Mammalia depicta. (Parey, Berlin, 1968).

${ }^{6}$ McHugh, T., Zoologica, 43, 1 (1958)

7 Frädrich, H. Handbuch der Zoologie, 8, 10, 16 (De Gruyter, Berlin, 1967).

${ }^{8}$ Schaller, G. B., Natn. geogr. Mag., 135, 494 (1969)

- Schaller, G. B., The Serengeti Lion. (University of Chicago Press, Chicago and London, 1972)

${ }^{10}$ Schenkel, R., Am. Zool., 7, 319 (1967).

11 Heptner, W. G., Nasimovitch, A. A., and Bannikov, A. G., Die Säugetiere der Sowjetunion. (Fischer-Verlag, Jena, 1961).

12 Ulrich, R. E., and Azrin, N. H., J. exp. Analysis Behav., 5, 511 (1962).

13 Azrin, N. H., Hutchinson, R. R., and McLaughlin, R., J. exp. Analysis Behav., 8, 171 (1965).

14 The Behaviour of Ungulates and its Relation to Management (edit. by Geist, V., and Walther, F.) (International Union for the Conservation of Nature, Morges, in the press).

15 Linsdale, J. M., and Tomich, P. Q., $A$ Herd of Mule Deer (University of California Press, Berkeley and Los Angeles, 1953). 